CrimRxiv

\title{
A conservation criminology-based desk assessment of vulture poisoning in the Great Limpopo Transfrontier Conservation Area
}

Meredith L. Gore, Annette Hübschle, André J. Botha, Brent M. Coverdale, Rebecca Garbett, Reginal M. Harrell, Sonja C. Krüger, Jennifer M. Mullinax, Lars J. Olson, Mary Ann Ottinger, Hanneline Smit-Robinson, L. Jen Shaffer, Lindy J. Thompson, Linda van den Heever, William W. Bowerman

Published on: Jul 01, 2021

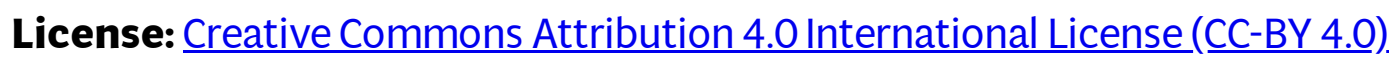


